\title{
Sudden death in a patient with a short PR interval and subsequent sudden onset of a typical Tako-tsubo pattern
}

\author{
Francisco R. Breijo-Marquez ${ }^{1}$, Manuel Pardo Rios ${ }^{2}$ \\ ${ }^{1}$ Conmemorative Hospital, East Boston, USA \\ ${ }^{2}$ School of Medicine, Murcia, Spain \\ Email: frbm@gmx.us, mpardo@pdi.ucam.edu
}

Received 1 December 2011; revised 1 January 2012; accepted 16 January 2012

Copyright (C) 2013 Francisco R. Breijo-Marquez, Manuel Pardo Rios. This is an open access article distributed under the Creative Commons Attribution License, which permits unrestricted use, distribution, and reproduction in any medium, provided the original work is properly cited.

\begin{abstract}
The Tako-tsubo cardiomyopathy, also known as transient apical dysfunction, transient apical dyskinesia, stress-induced cardiomyopathy or broken heart syndrome, is a type of nonischemic cardiomyopathy in which there is a sudden temporary weakening of the myocardium. The PR interval reflects the time the electrical impulse takes to travel from the sinus node through the AV node and entering the ventricles. The PR interval is therefore a good estimate of AV node function. Its normal values are between $0.120-0.200$ seconds. When its length is lesser than 0.120 seconds, we speak as a short PR-interval. This event has a great capacity for severe cardiac arrhythmia production. Both entities can be very dangerous, separately. When they are together in the same individual, the consequences could be deadly.
\end{abstract}

Keywords: Takotsubo Disease; Short PR-Interval; Lown-Ganong-Levine; Tachycardias

\section{INTRODUCTION}

Takotsubo disease is being widely studied in recent times, and different terms have been used to describe the disorder. This form of cardiomyopathy is usually caused by physical or emotional stress and is of a non-ischemic nature characterized by sudden temporary weakening of the myocardium [1,2]. Such sudden weakness can be triggered by physical or emotional stress [3], as in the case of the death of a loved one. For this reason, the disease is often also known as "broken heart syndrome". It has also been reported in cases of partial drowning.

The typical presentation of Takotsubo cardiomyopathy comprises sudden-onset congestive heart failure or chest pain associated with electrocardiographic abnormalities suggestive of acute myocardial ischemia of the anterior wall [4]. Throughout the course of the evaluation of the patient, we often observe a bulging of the left ventricular apex with basal hypercontractility of the left ventricle (as established by echocardiography). This is the main characteristic of Takotsubo disease, which means "octopus trap" in Japanese (the first case of the disorder being reported in Japan).

The underlying cause appears to involve high levels of circulating catecholamines (mainly adrenaline/noradrenaline) $[1,3,4]$, but this aspect has not been studied in depth. Further studies are therefore needed to confirm this origin of the disease.

Another very important feature in Takotsubo disease is that the blood levels of the typical cardiac markers of myocardial infarction are normal or only very discreetly elevated.

The evaluation of patients with Takotsubo cardiomyopathy typically includes coronary angiography, which may not reveal significant obstructions capable of causing left ventricular dysfunction.

Among survivors of the initial presentation of the disease, left ventricular function is seen to improve within two months [4].

Takotsubo cardiomyopathy looks be more common in postmenopausal women, and patients usually present a recent history of severe physical or emotional stress [1-4].

A Short PR-Interval $[5,6]$ may be associated with an otherwise normal electrocardiogram or an untold number of bizarre electrocardiographic abnormalities. Clinically, the individual may be asymptomatic or experience a variety of complex arrhythmias, which may be disabling but rarely cause sudden death. 
It is measured from the beginning of the P-wave to the beginning of the QRS complex. The normal PR-interval measures 0.12 to 0.20 seconds in length.

A short AV conduction time, whether associated to a normal or abnormal QRS complex, is correlated to an increased incidence of paroxysmal tachycardias [4,5]. A considerable number of patients have a short PR-interval, a normal QRS complex and bouts of tachycardia. Evidence is presented suggesting the action of endocrine and autonomic nervous system factors in the origin of both the short PR-interval and Takotsubo disease.

Nevertheless, the coexistence between Takotsubo disease and a short PR-interval has been little studied to date [7].

In 1952, Lown, Ganong and Levine (L-G-L) described an abnormal shortening of the PR-interval regarded as a pre-excitation syndrome, a case of true accelerated atrioventricular conduction. L-G-L syndrome may affect about $1 / 50,000$ persons. In the absence of significant structural heart disease, the mortality rate appears to be low, though fatalities are not uncommon. Patients may experience an acute episode of tachycardia or a history of symptoms suggestive of paroxysmal tachycardia. Sudden death is caused by the presence of ventricular fibrillation, it is not previously diagnosed and treated.

\section{SHORT COMMUNICATION}

We report a case in which this association can be seen.

A 54-year-old Caucasian woman had lost her husband 6 days ago. She was rushed to hospital due to sudden dyspnea and oppressive chest pain suggestive of acute coronary syndrome. She was transferred to the emergency room of our center by ambulance.

Once in the emergency room, the cardiologists requested an electrocardiogram, echocardiography, and subsequently angiography. A blood test was also requested, placing special emphasis on cardiac markers. Blood testing showed no increase in cardiac markers. Troponin (I, T) proved normal, in the same way as CPK, CK, LDH (this being another common feature of Takotsubo disease). Repeated cardiac marker testing 4 and 8 hours after first determination also proved normal, thus confirming severe myocardial suffering rather than manifest muscle damage as such.

The electrocardiogram showed signs of cardiac ischemia (Figure 1).

Echocardiography in turn showed acute left ventricular dilatation (Figure 2).

Angiography revealed no obstructive lesions in any coronary artery (Figure 3).

Ventriculogram showed the typical ballooning in Takotsubo disease (Figure 4).

Important findings were the fact that her husband had died 6 days earlier, as well as a clinical history of sudden

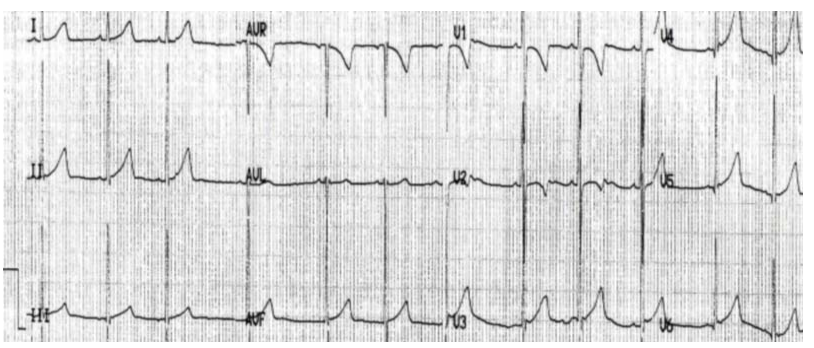

Figure 1. We can see an ECG with signs of acute ischemia, steepest in right precordial leads.

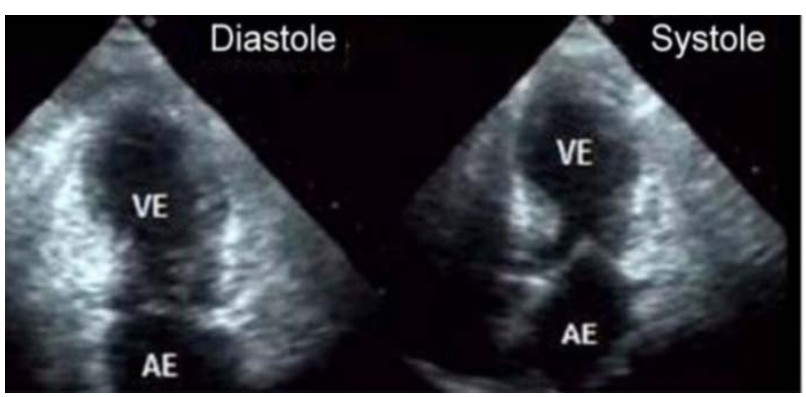

Figure 2. We can see on echocardiography, the typical dilation of the left ventricle in cases of Takotsubo.
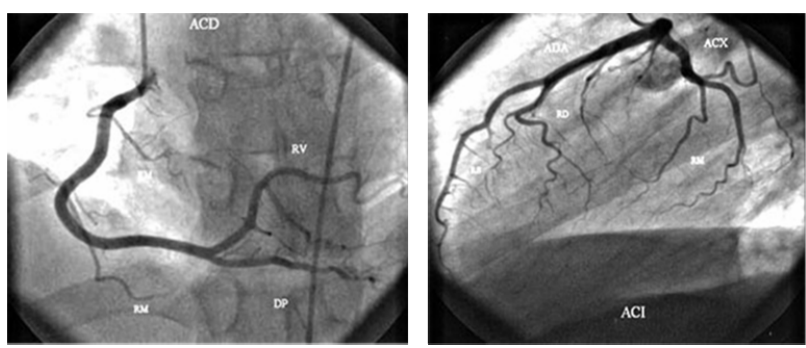

Figure 3. We can see a normal angiography, unobstructed.

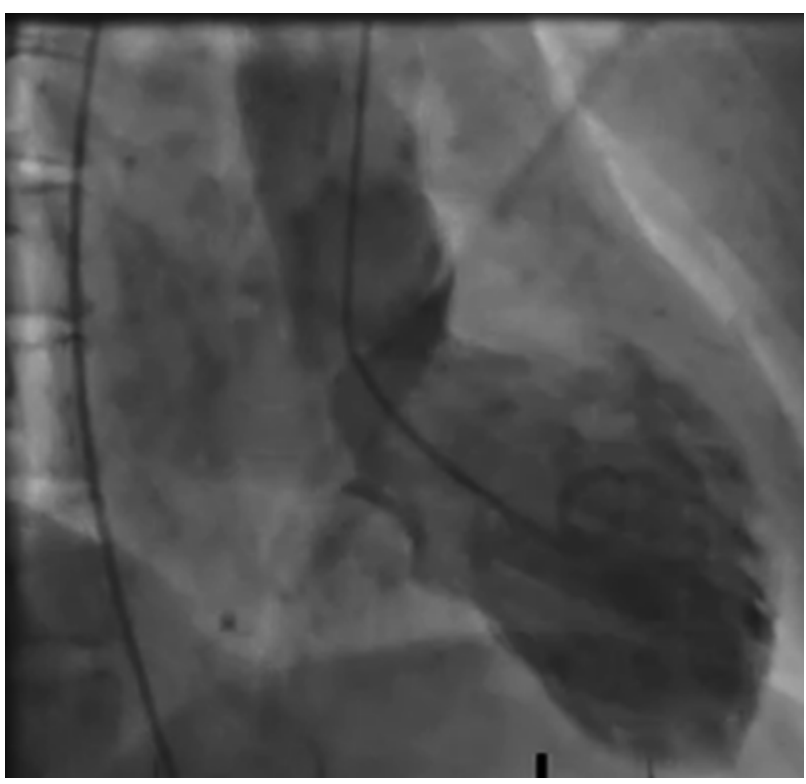

Figure 4. We can see the typical image of ballooning from Ventriculogram. 
tachycardias from her childhood, fundamentally at rest.

Following stabilization of the acute event, the patient was closely monitored. The blood cardiac marker levels remained normal. The electrocardiographic abnormalities also normalized, except for the length of the PR-interval. The echocardiographic anomalies were not seen to persist.

The case was diagnosed as Takotsubo disease; however, a short PR-interval, less 0.120 sec. in length, can be seen on all 12 leads on her ECG tracing (she was confirmed like a Lown-Ganong-Levine pattern by posterior genetic studies; she was positive for PRKAG2 gene).

Following the prescription of appropriate treatment for cardiac ischemia, the patient was discharged from hospital.

However, the short PR-interval was not diagnosed.

More often than we think, this feature might be present but is overlooked.

The presence of a short PR-interval would be an added risk factor for new cardiac events such as sudden tachycardia in bursts $[5,6]$, and particularly life-threatening as ventricular tachycardia or fibrillation.

In fact, our patient died suddenly at her home ten days after being discharged from hospital. It was clearly a preventable death if the short PR interval had been diagnosed correctly. Unfortunately, it was not.

We have already published more than one case with these features [7].

It therefore must be stressed that this disorder exists and should not overlooked.

The presence of a short PR-interval is also present in other cardiac diseases as in the Wellens echocardiographic pattern, as we have shown [7].

\section{SUMMARIZING}

Takotsubo disease is being increasingly studied, but we do not know still its fundamental etiology. Its occurrence is not uncommon in individuals with previous cardiac electrical disorders. The prognosis may be bleak when both circumstances manifest in the same individual. Evaluation of an altered PR-interval always should be made before hospital discharge.

Diagnostic errors that quietly occur in the mind of the clinician are the most frequent, most severe, and most costly of all medical mistakes.

\section{REFERENCES}

[1] Eshtehardi, P., Koestner, S.C., Adorjan, P., et al. (2009) Transient apical ballooning syndrome-Clinical characteristics, ballooning pattern, and long-term follow-up in a Swiss population. International Journal of Cardiology, 135, 370-375. doi:10.1016/j.ijcard.2008.03.088

[2] (2006) Mayo clinic research reveals "broken heart syndrome" recurs in 1 of 10 patients. Science News, 20 November 2006.

[3] Akashi, Y.J., Nef, H.M., Mollmann, H. and Ueyama, T. (2010) Stress cardiomyopathy. Annual Review of Medicine, 61, 271-286. doi:10.1146/annurev.med.041908.191750

[4] Azzarelli, S., Galassi, A.R., Amico, F., et al. (2006) Clinical features of transient left ventricular apical ballooning. American Journal of Cardiology, 98, 1273-1276. doi:10.1016/j.amjcard.2006.05.065

[5] MacKenzie, R. (2005) Short PR interval. Journal of Insurance Medicine, 37, 145-152.

[6] Miles, W.M. and Zipes, D.P. (2000) Atrioventricular reentry and variants: Mechanisms, clinical features, and management. In: Zipes, D.P. and Jalife, J., Eds., Cardiac Electrophysiology: From Cell to Bedside, 3rd Edition, WB Saunders, Philedelphia, 638-655.

[7] Breijo-Márquez, F.R., Pardo Ríos, M. and Alcaraz Baños, M. (2010) Presence of a critical stenosis in left anterior descending coronary artery alongside a short "P-R" and "Q-T" pattern, in the same electrocardiographic record. Journal of Electrocardiology, 43, 422-424. doi:10.1016/j.jelectrocard.2010.03.002 